\title{
GÊNERO E RELIGIÃO: UMA TRILHA NA FORMAÇÃO DE PROFESSORES
}

\author{
Gender and religion: a trail in teacher training
}

Género y religión: un camino en la formación de los professores

\author{
Darli de Fátima Sampaio* \\ Rosa Lydia Teixeira Corrêa*
}

\begin{abstract}
Resumo
O presente artigo é parte de tese de doutorado cujo interesse investigativo contempla duas categorias centrais na conjuntura política e social contemporânea: gênero e religião, ambas com incidência no campo educacional. Parte da percepção das autoras de que o campo religioso tradicional e conservador, tanto católico como protestante, que se referenciam em representações tradicionais sobre sexo e gênero, buscam não só uma polarização moral, e o aniquilamento do conceito de gênero nas escolas, mas também uma possível qualificação de um corpo docente alinhado com tal estratégia. Realizou-se uma pesquisa junto a estudantes de Pedagogia de uma universidade confessional e outra pública no Estado do Paraná, no município de Curitiba para conhecer o grau de entendimento e concordância sobre as Teorias de Gêneros; os dados preliminares permitem concluir que discussões sobre gênero vão estar presentes nas escolas independente do desejo do campo religioso conservador.
\end{abstract}

PALAVRAS-CHAVE: Gênero. Educação. Religião.

\begin{abstract}
This article is part of a doctoral thesis which is interested in investigating two central categories in the contemporary political and social scene: gender and religion, both related to the educational field. It departs from the authors' perception that the traditional and conservative religious field, either Catholic or Protestant, both sharing a traditional representation about sex and gender, seek not only a moral polarization, an annihilation of the concept of gender in schools, but also the possible qualification of a great number of teachers aligned with such strategy. The research was made with Pedagogy students from a confessional and a public university in Curitiba, capital of Parana state, aiming to know the students' degree of understanding and agreement as far as the Gender Theories; the preliminary results indicate that discussions about gender will continue to be present at schools, despite the desire of the religious conservative groups.
\end{abstract}

KEYWORDS: Gender. Education. Religion.

\section{Resumen}

\footnotetext{
* Doutoranda do Programa de Pós-Graduação em Educação da Pontifícia Universidade Católica do Paraná e Professora da Pontifícia Universidade Católica do Paraná (PUCPR). E-mail: darli.sampaio@pucpr.br

* Professora do Programa de Pós-Graduação em Educação, Mestrado e Doutorado da Pontifícia Universidade Católica do Paraná(PUCPR) . E-mail: rosa.correa@pucpr.br
} 
El presente artículo es parte de una tesis de doctorado cuyo interés investigativo contempla dos categorías centrales en la coyuntura política y social contemporánea: género y religión, ambas con incidencia en el campo educativo. Parte de la percepción de las autoras de que el campo religioso tradicional y conservador, tanto católico como protestante, que se referencian en representaciones tradicionales sobre sexo y género, buscan no sólo una polarización moral, y el aniquilamiento del concepto de género en las escuelas, pero también una posible cualificación de un cuerpo docente alineado con tal estrategia. Se realizó una investigación junto a estudiantes de Pedagogía de una universidad confesional y otra pública de la provincia de Paraná, ciudad de Curitiba, para conocer el grado de entendimiento y concordancia sobre las Teorías de Géneros. Datos preliminares permiten concluir que discusiones sobre género vanestar presentes en las escuelas independiente del deseo del campo religioso conservador.

PALABRAS CLAVE: Género. Educación. Religión.

\section{INTRODUÇÃO}

"Hear not the frantic cries of the leaders who in that they seek to lead desert us". Virgínia Woolf ${ }^{1}$

O presente artigo é o resultado parcial de pesquisa realizada em tese de doutorado. Tem por objetivo analisar as representações (CHARTIER, 1990) de gênero ${ }^{2}$ desenvolvidas pelo campo ${ }^{3}$ religioso. Para tanto, toma como referência as Igrejas Católica Apostólica Romana ${ }^{4}$ e a Protestante. A primeira por meio de segmentos conhecidos como tradicionais ${ }^{5}$ e conservadores, e a segunda nas denominadas Pentecostal Assembléia de Deus (AD) e Neopentecostal Igreja Universal do Reino de Deus (IURD). Orienta-se metodologicamente pela abordagem da História Cultural ${ }^{6}$, compreensão historiográfica que apresenta múltiplas possibilidades de objeto de estudo, oferecendo o suporte necessário para a análise de micro histórias, evidenciando protagonistas anônimos, não contemplados pela historiografia tradicional. Possibilita a investigação sobre amplo espectro de interesses temáticos não tratados na tradição historiográfica 7 .

\footnotetext{
${ }^{1}$ WOLF, 1992, p. 156. Tradução livre: "Não ouçam os gritos frenéticos dos líderes que buscam nos conduzir para o deserto".

${ }^{2}$ Para Pedro (2005, p. 78), o uso da palavra gênero "tem uma história que é tributária de movimentos sociais de mulheres, feministas, gays e lésbicas, e uma trajetória que acompanha a luta por direitos civis, direitos humanos, enfim, igualdade e respeito".

${ }^{3} \mathrm{O}$ conceito de campo, que será utilizado ao longo do presente trabalho tem por referência a obra: $O$ poder simbólico, de Bourdieu (1989). A compreensão de campo do autor evidencia interesses, linguagens, regras e premiações, hierarquias, entre outras, que são próprias de cada campo.

${ }^{4}$ De acordo com a publicação no site "Catolicismo Romano", KATHOLICOS, significa "universal", geográfica e conceitualmente, "apostólica" de apóstolos, e "romana” de local, Roma. Disponível em: <https://www.catolicismoromano.com.br/content/view/1102/43/> . Acesso em: 13 dez. 2018.

${ }^{5}$ Principais segmentos tradicionais e conservadores estudados: Opus Dei, Instituto Plínio Corrêa de Oliveira - IPCO, Associação Cultural Montfort e Arautos do Evangelho.

${ }^{6}$ Surge em 1929 por iniciativa de dois historiadores: Marc Bloch e Lucien Febvre, a partir da publicação da Ecole dês Analles, da revista: Annales d'historie économique et sociale. "Posicionou-se contrária à historiografia positivista e aos aspectos políticos, rejeitando, assim, toda política vigente, o capitalismo, os regimes totalitários e o modelo soviético, ideologias presentes nos anos 20 e 30" (DOSSE, 1992, apud STEIN, 2004, p. 1).

${ }^{7}$ Maria Izilda de Matos, em seu artigo intitulado, Gênero: categoria/perspectiva e constituição do campo historiográfico apresenta uma série de temas de gênero abordados no campo historiográfico (MATOS, 2017).
} 
A educação destaca-se no cenário nacional brasileiro atual como centro de tensões políticas, sinalizando um projeto educacional religioso que advoga certo primado moral com base em um "conservadorismo dogmático cristão" (TADVALD, 2015 , p. 262) para a sociedade contemporânea, numa tentativa de consolidar projetos estratégicos que formam uma tríade de poder religioso: comunicação, política e educação. Os dois primeiros projetos já alcançados pelo campo religioso, que agora avança para o terceiro elemento da tríade: o campo educacional.

No ano de 2018, no Estado do Paraná, na cidade de Curitiba, durante o doutorado foi realizada pesquisa junto a estudantes do curso de Pedagogia de uma universidade confessional e outra pública, com o objetivo de averiguar se há vestígios de representações dogmáticas nas declarações de estudantes que pudessem condicionar a sua percepção sobre as questões de gênero. Na tentativa de também compreender como estes (as) se veem enquanto sujeitos de saber e de interação nas suas futuras instituições de ensino, bem como o nível de entendimento sobre as Teorias de Gênero e o grau de concordância sobre alguns temas propostos ou defendidos pelo campo religioso, a exemplo da Escola Sem Partido (ESP), que tenta "alinhar" e prescrever comportamentos de docentes contra questões consideradas ideológicas. O Curso de Pedagogia, historicamente é composto em sua maioria por mulheres ${ }^{8}$, e estas representam a grande base das Igrejas.

\section{Representações de gênero em interface com a "ideologia de gênero"}

As igrejas citadas anteriormente evidenciaram, a partir das eleições de 2014, um impressionante projeto de crescente inserção política. Setores religiosos compostos por tradições históricas, profusas, tornaram visível um processo de planejamento estratégico de poder, facilitada por uma consolidada presença e influência nos varia dos meios de comunicação ${ }^{9}$ informação social. Tal estratégia comunicacional resultou na eleição de uma bancada religiosa conservadora, que acabou por constituir a Frente Parlamentar Evangélica (FPE), capaz de construir aliança com parlamentares católicos em vista de temas comuns, situados no campo da moral e dos costumes, dispostos, especialmente, a combater um constructo narrativo chamado de "ideologia de gênero". O ativismo religioso no Congresso Nacional passou a desqualificar sistematicamente qualquer discussão sobre questões de gênero e sexualidade, que estavam no epicentro das estruturas que formulavam políticas públicas no país, e reinventou a histórica relação religião e política, demonstrando, na prática, que a transcendência não é apenas um fenômeno religioso, mas também ideológico, e fundamentalmente político.

Parlamentares religiosos e setores ultraconservadores do Congresso Nacional, em uma ancoragem discursiva bio-religiosa, com defesa da naturalização do gênero e do

\footnotetext{
${ }^{8}$ Para Pedro (2005), não existe um conceito universal de mulher. Várias são as mulheres: pobres, indígenas, negras, deficientes, mestiças, idosas, religiosas etc. São identidades e problemáticas diferenciadas, com pauta reivindicatória própria e para "as historiadoras e historiadores que passaram a seguir a tradição da historiografia dos Annales - que pretendia ampliar o leque de fontes e observar a presença de pessoas comuns -, tornou-se mais fácil escrever uma história que incluísse as mulheres". Pedro (2005, p. 85)

${ }^{9}$ De acordo com o Coletivo Intervozes e Repórteres Sem Fronteiras, os grupos religiosos de matriz cristã têm aumentado participação no controle da mídia. Disponível em: http://www.ihu.unisinos.br/575908igrejas-controlam-9-dos-50-veiculos-mais-influentes-do-pais-mostra-pesquisa. Acesso em: 8 fev. 2018.
} 
sexo, deflagraram guerra semântica e reativa contra a "ideologia de gênero" ${ }^{10}$ "e outras possibilidades de existência humana, que "explodem" as percepções binárias e as construções sociais de gênero, cultivadas pelas Igrejas com papéis e comportamentos inexoráveis para homens e mulheres. Além, evidentemente, da necessidade de impedir os avanços conquistados pelas pesquisas em gênero (REIS; EGGERT, 2017).

São veiculados discursos e ações "com base em dogmas e posições religiosas, com elevado enaltecimento e prezo pela família, e circunscrita a uma configuração tradicional, ou seja, nuclear, consagrada no matrimônio, com arranjo" (SILVA, 2017, p. 27) e ordem tradicionais, hierarquizadas: pai, mãe e filhos. Contém alegações de supostas violações de leis divinas e de pisoteamento de valores religiosos -rejeitando projetos e políticas públicas para a diversidade (principalmente as do âmbito educacional) sob alegação de que estavam gerando posturas impositivas às crianças sobre uma ideologia baseada em princípios antinaturais e antifamiliares.

Para alguns pesquisadores (as) de gênero, tratava-se de um ato antidemocrático, contrário à laicidade do Estado, além de tentativa de deslegitimar toda uma área de conhecimento reconhecida e relevante para as práticas educacionais, especialmente no combate às variadas violências de gênero. Todavia as ações articuladas do campo religioso conservador acabaram por impactar a educação, com a retirada do conceito de gênero e diversidade do Plano Nacional de Educação (PNE/2014-2024) e, posteriormente, nos Planos Estaduais e Municipais.

O meta-conceito "ideologia de gênero" é debitado, enquanto criação teórica, à Igreja Católica. A primeira referência ao conceito, segundo Silva (2017), vem de um documento eclesial, a nota emitida pela Conferência Episcopal do Peru em 1998, intitulado La ideologia de gênero: sus peligros y alcances, alertando que, entre os vários perigos, encontra-se a necessidade de proteger a família contra os defensores de tal ideologia que tentam promover a desconstrução da família, da educação, da cultura e da religião (CONFERÊNCIA EPISCOPAL PERUANA, 1998). O que acabou por desembocar em confronto e ativismo religioso contra o conceito de gênero, tornando-o o centro do debate e de ações legais, dando-lhe visibilidade de forma a extrapolar as fronteiras universitárias e de alguns movimentos sociais. A reação da Igreja Católica e demais Igrejas, especialmente as Pentecostais e Neopentecostais, promoveu o gênero e a "ideologia de gênero", ampliando o conhecimento sobre estes, para o bem e para o mal, nas narrativas especializadas, religiosas ou nos debates livres, que circularam nas mídias sociais. Estas acompanhavam com elevada preocupação os avanços que os estudos de gênero contabilizavam, resultado de inúmeros esforços de analistas, bem como dos movimentos sociais, para desnaturalizar, no plano discursivo e de ações afirmativas, os pressupostos essencialistas que legitimam e justificam a desigualdade de gênero, que vitimiza especialmente as mulheres. Em nível internacional, o tema gênero vinha tomando corpo progressivamente, vinculado às questões referentes aos Direitos Humanos, ocupando espaço em congressos, conferências, simpósios, e discutido de forma aprofundada.

Neste sentido, vale destaque para a IV Conferência Mundial sobre as Mulheres, em Pequim em 1995, que deliberou pela compreensão do conceito de gênero enquanto uma construção social; e os Princípios de Yogyakarta que tratou da Aplicação da

\footnotetext{
${ }^{10}$ Utilizaremos o conceito "ideologia de gênero" entre aspas porque partimos do entendimento que o conceito foi criado para deslegitimar e desmerecer os estudos de gênero produzidos no campo acadêmico.
}

Educação e Fronteiras On-Line, Dourados/MS, v.9, n.26 p.22-34, maio/ago. 2019 
Legislação Internacional de Direitos Humanos em Relação à Orientação Sexual e Identidade de Gênero (2007), ratificadas pelo Brasil. O conceito de gênero, no meio social, vincula-se à identificação de desigualdades entre homens e mulheres, que vem sendo fortemente questionadas no Brasil pelo campo religioso. Trata-se de uma desigualdade de papéis e vantagens sociais construídos a partir do biológico, facilmente identificável na sociedade, no mundo científico, religioso e político, traduzida em uma posição desfavorável e de subalternidade para as mulheres, que parecem "invisíveis" enquanto sujeitos históricos, "mas uma invisibilidade não significa ausência" (SCOTT, 2002, p. 73). Embora proliferem discursos que defendem a inclusão compartilhada de mundo, estas ficam restritas às boas intenções discursivas. Buttler, que tem enfrentado fortes reações do campo religioso, afirma que a "diferença sexual, entretanto, não é, nunca, simplesmente, uma função de diferenças materiais, que não sejam de alguma forma, simultaneamente, marcadas por práticas discursivas" (BUTTLER, 1999, p. 151). Romper com tais práticas significa adotar uma posição de desnaturalização do sexo, do corpo, dos gêneros, e este entendimento acaba por promover uma transformação que afeta sobremaneira a forma como entendemos a relação entre os seres humanos, especialmente as relações de poder (SCOTT, 1995).

A polêmica estabelecida com o campo religioso tradicional, conservador, centrase no debate teórico estabelecido entre natureza-cultura, que abala as relações de poder estabelecidas pela hegemonia da heteronormatividade ${ }^{11}$, que se expressa no corpo. Não é apenas um dado da cultura, mas também do lugar prático, direto do controle social. Pela prática automática, reiterada, habitual a cultura se faz no corpo. A relação entre cultura e natureza, pressuposta por modelos do gênero como construção, supõe uma cultura ou uma agência do social que age sobre a natureza, a qual é ela própria pressuposta como uma superfície passiva, fora do social, mas uma necessidade que se configura enquanto uma área para reflexão, aprofundamento e desenvolvimento de propostas teóricas sobre a organização social e as relações vividas entre os sexos, especialmente.

Como já mencionado anteriormente a pesquisa foi realizada durante o ano de 2018, em duas universidades, uma confessional (UC) e outra pública (UP), junto a estudantes do curso de pedagogia de $1^{\circ}$ e $8^{\circ}$ períodos e $1^{\circ}$ e $3^{\circ}$ anos, e contou com a participação voluntária de 121 estudantes. Realizada por meio da aplicação de questionário estruturado (SEVERINO, 2016), composto por 25 questões fechadas e 15 questões abertas, num total de 40 questões, com o objetivo de tomar as respostas dos (as) estudantes como objeto de análise, sobre os conhecimentos, entendimentos, grau de concordância e representações que tais estudantes apresentam sobre questões de gênero e a sua relação com o campo religioso.

A aplicação do questionário se deu em um ano marcado por intensas polêmicas, debates contundentes e tramas discursivas produzidas especialmente pelas igrejas e parlamentares cristãos, sobre questões emanadas do conceito de gênero, sexualidade, valores, educação e família. Configurou-se em uma forte fronteira a relação entre família e educação, ou melhor, a função da família com relação à educação, bem como a função da educação com relação aos (as) educandos (as), repercutindo nos debates sobre

\footnotetext{
${ }^{11}$ Para Tamsin Spargo (2006, p. 67) a heteronormatividade - [...] especifica a tendência, no sistema sexogênero, de ver as relações heterossexuais como a norma, e todas as outras formas de comportamento sexual como desvios dessa norma (grifos da autora).
} 
os Planos de Educação, que abrigavam o conceito de gênero e diversidade, nas políticas governamentais.

A abordagem utilizada na pesquisa foi quanti-qualitativa, considerando a interação com processos culturais, sociais e políticos, propiciando uma investigação com atenção analítica profunda, reconsiderando as experiências de homens e mulheres comuns, na maioria das vezes invisibilizados na história, como apregoa a História Cultural. Recupera o cotidiano, as ações, fundamenta a importância da análise dos discursos, das práticas sociais dos agentes e das representações postas (TAMANINI, BOSCHILIA, SCHWENDLER, 2017). Narrativas que evidenciam a subjetividade, a singularidade, do sujeito pesquisado, evidenciando "uma preocupação cada vez maior com as pessoas comuns e as maneiras pelas quais elas dão sentido às suas experiências, suas vidas, seus mundos" (BURKE, 2008, p. 158). As representações que têm do mundo possibilitam o entendimento sobre, em que medida, as práticas religiosas podem ser colocadas a serviço de um projeto pastoral estratégico a ser executado no exercício da profissão, mesmo que as (os) executantes não tenham, em princípio, consciência da lógica do projeto ao qual foram de certa forma, colocadas (os) a serviço.

A Pedagogia apresenta um corpo tanto docente como discente formado por forte recorte de gênero, majoritariamente feminino. Louro, analisando as diferentes instituições constituídas pelos gêneros, diz que elas também as constituem, ou seja, as "instituições e práticas não somente "fabricam" os sujeitos como também são, elas próprias, produzidas (ou engendradas) por representações de gênero, bem como por representações étnicas, sexuais, de classe etc.,"(LOURO, 1997, p. 88).

\section{Questões de gênero, perfil religioso e práticas religiosas}

Por identidade de gênero ${ }^{12}$ entende-se o gênero com o qual uma pessoa se identifica, ou seja, que ela sente que de fato é. A identidade de gênero "pode ou não concordar com o gênero que lhe foi atribuído quando de seu nascimento. Diferente da sexualidade da pessoa. Identidade de gênero e orientação sexual são dimensões diferentes e que não se confundem" (JESUS, 2012, p. 24), pois, as "pessoas transexuais podem ser heterossexuais, lésbicas, gays ou bissexuais, tanto quanto as pessoas cisgênero" (JESUS, 2012, p. 24).

A primeira pergunta que adentra às questões do campo de gênero inquiriu sobre a sua própria orientação sexual/identidade de gênero. Obtivemos as seguintes respostas: heterossexuais declarados são majoritários, representando 79 estudantes na UC e 27 na UP; somados os dados das duas universidades pesquisadas, são 106 heterossexuais no total (87,60\%). Homossexuais: $05(4,13 \%)$ e bissexuais: 9 (7,44\%). Uma pessoa não respondeu.Julgamos não ser necessário incluir no questionário uma solicitação de definição, visto a evidência de não categorizar. Ninguém se declarou assexual nem indicou outra orientação.

Sobre a questão da cisgeneralidade, na origem etimológica o prefixo "cis", em latim, significa "do mesmo lado" ou "ao lado de" e refere-se a pessoas que estão em concordância com o seu gênero de nascença, ou seja, não há divergência alguma, pois

\footnotetext{
${ }^{12}$ Orientações sobre identidade de gênero: conceitos e termos - Guia técnico. Disponível em: $<$ http://www.diversidadesexual.com.br/wp-content/uploads/2013/04/G\%C3\%8ANERO-CONCEITOS-ETERMOS.pdf $>$. Acesso em: 10 jan. 2019.
} 
se identificam com o seu gênero de nascimento. Foram 113 estudantes que declararam ser mulher "cisgênero", 5 estudantes se declararam homem "cisgênero". A opção "sexo não binário "13" não foi oferecida nem selecionada a alternativa "mulher ou homem transgênero" (com mudanças no corpo). Mas uma das alternativas oferecia a possibilidade da opção "outra" para a identidade de gênero, e esta foi a alternativa selecionada por duas pessoas da UP, sendo que uma delas declarou-se evangélica. Todavia, sem maiores dados sobre a sua identidade de gênero. E uma estudante não respondeu.

Quando perguntados se acreditavam em Deus, no $1^{\circ}$ período da UC, 57 estudantes, expressiva maioria, declaram-se crentes $(95,00 \%)$. Não crentes foram 03 estudantes $(5,00 \%)$. A turma do $8^{\circ}$ período declarou-se crente em Deus $(100 \%)$. No total das turmas, 116 deles (as) $(95,87 \%)$ declararam-se crentes, 05 estudantes disseram que não $(4,13 \%)$, sendo 3 da UC e 2 da UP. Os dados coletados demonstram um elevado número de estudantes que declararam crença em Deus, majoritariamente mulheres com práticas de participação em igrejas, ainda que, do ponto de vista institucional, as igrejas tenham trajetórias similares de certa "negação" histórica da dignidade feminina, construindo uma representação da mulher enquanto um ser historicamente "desprezível e perigoso por sua especial sexualização" (FORCANO, 1995, p. 121), justificada por uma "leitura masculinizante da Bíblia" (FORCANO, 1995, p. 125). Assim, cabe indagar: por que mulheres com acesso a tantas informações se mantém vinculadas às instituições patriarcais, sem as questionarem, como as igrejas?

A partir da pergunta posta, considerou-se a possibilidade de insurgência das mulheres (pedagogia) com relação às questões de gênero. Consideroque o fato de uma forte vinculação delas às instituições religiosas não significa que compartilhem de todas as suas ideias nem que estejam a favor da Igreja. Falquet (2014), analisando as reflexões de Mathieu (1991), aborda reflexões da autora em um texto intitulado "quando ceder não é consentir" (1991), enfrentando posicionamentos de intelectuais que afirmavam que as mulheres "consentiriam" com a dominação sobre elas (FALQUET, 2014, p.17). A palavra "dominação" poderia até despertar sentimentos lisonjeiros nos homens, por serem "dominantes"; mas no caso das mulheres, o termo mais adequado a usar seria "opressão", por apresentar a ideia de violência e sufocamento. Falquet (2014), explica que para Mathieu:

[...] as mulheres não têm acesso às mesmas informações sobre a 'sua' cultura que os homens - seja no acesso à alfabetização, à educação científica ou sexual, ou aos conhecimentos religiosos, filosóficos ou esotéricos (...) não teriam que ser obrigadas a se alinhar a um campo ou a outro, já que 'seus' próprios homens lhes excluem em geral da definição, da plena participação e da possibilidade de encarnar a versão mais legítima da 'sua' cultura. (...) a explicação no caso das mulheres, daquilo que outras pessoas começaram a teorizar simultaneamente para 'raça' ou na perspectiva da imbricação entre sexo e 'raça', e que eu proponho chamar de esquizofrenia legítima e política das minorias. (FALQUET, 2014, p. 17).

\footnotetext{
${ }^{13}$ Esta opção entrou no trabalho como uma possibilidade de localizar as pessoas queers. É importante ressaltar porque o conceito "não binário" é muito amplo, abrangendo várias possibilidades.
} 
As hierarquias eclesiais são refratárias ao arcabouço filosófico das teorias feministas, que buscam a inclusão da mulher na ordem política, econômica, social, cultural e religiosa, o alargamento da democracia, a possibilidade de decisão sobre o seu corpo, entre outras. Várias manifestações e atos políticos feministas chocaram e provocaram reações da moralidade religiosa do campo religioso conservador, que resiste à participação plena das mulheres nos cargos de decisão e justificam a desigualdade de gênero em uma vontade divina. Entre os (as) estudantes, 95 deles (as) $(78,51 \%)$ declararam seguir uma determinada religião; 27 estudantes (22,31\%) declararam que não. Uma estudante respondeu a alternativa "sim" e "não", portanto foi contada duas vezes.

Constata-se um pluralismo no campo religioso, perceptível nos cursos de Pedagogia pesquisados. Na soma das declarações dos estudantes das duas universidades localizei as seguintes religiões: Católica: 55 estudantes (45,45); Evangélica Pentecostal: 18 estudantes (14,88); Protestantes tradicionais: 7 estudantes; Espírita: 5 estudantes $(4,13)$; Cristã: 3; Adventista 2 (1,65); Budismo, Candomblé e Judaica, cada uma indicada por um (a) participante. A alternativa "outra" foi escolhida por 04 estudantes $(3,31 \%)$, e entre eles (as) um (a) declarou ser Mórmon. Nas respostas, um (a) estudante marcou a alternativa "pentecostal" e na alternativa outra, novamente escreveu "pentecostal". Outra declarou ser católica e espírita, e outra, marcou a alternativa "católica" e "umbandista". E vinte e quatro estudantes não responderam essa questão.

Foram consideradas, na soma, as respostas dos (as) estudantes que disseram ser cristãos, ou seja, católicos, pentecostais, neopentecostais. Alguns estudantes parecem ter

dificuldades de localizar em qual campo a sua igreja se situa. É compreensível, pois, de acordo com pesquisadores do campo evangélico, (ALENCAR, 2015), (LOPES, 2018), (FAJARDO, 2016), a diversidade da composição do campo religioso protestante/evangélico, no que diz respeito às nomenclaturas, é grande.

\section{A pedagogia e as questões de gênero}

A pesquisa contemplou alguns dos temas polêmicos que mais aparecem nos debates de gênero na sociedade contemporânea. São eles: gênero, identidade de gênero, "ideologia de gênero", transexualidade, heterossexualidade, homossexualidade, bissexualidade, LGBTI, "cura gay", vivência homoafetiva e direito de decisão. O objetivo era conhecer o nível de conhecimento/entendimento dos (as) estudantes sobre os temas. Apresentaremos na sequência os resultados do entendimento declarado pelos (as) estudantes sobre alguns conceitos:

Sobre gênero: 1 estudante declarou saber pouco; 20 estudantes conhecem algumas questões; 23 estudantes declaram conhecimento mediano; 54 estudantes afirmam ter um conhecimento bom; e 23 estudantes declararam ter muito conhecimento. Então, foram 21 estudantes que reconhecem saber pouco; os que sabem medianamente são 23; e os que consideram que conhecem bem ou muito são 77 estudantes $(63,3 \%)$. Observa-se que o conhecimento sobre gênero parece relativamente bem distribuído, com um nível satisfatório sobre o assunto.

Em relação à identidade de gênero: 3 estudantes não sabem nada; 3 sabem pouco; 23 conhecem algumas questões; 18 conhecem mais ou menos; 58 têm conhecimento razoável/bom; 12 estudantes declararam saber muito sobre o tema; e 4 
não responderam. Nas respostas dadas, 70 estudantes $(57,8 \%)$ declararam conhecer bem o tema da identidade de gênero. Um número significativamente alto. Só 6 estudantes declararam não conhecer o tema.

As teorizações sobre o conceito de gênero, especialmente por segmentos tradicionais e conservadores religiosos, defendem as normas éticas sexuais absolutas do ensinamento magisterial, priorizando o físico e o biológico em detrimento do relacional. Posicionam-se em favor da complementaridade heterogenital e pessoal, como define a Nova Teoria da Doutrina Natural (NTDN) do campo católico, que também determina como imoral os atos homossexuais, por exemplo, por violarem não só a complementaridade heterogenital, mas também a reprodutiva, segundo Salzman e Lawler (2012).As representações de gênero (CHARTIER, 1990) para as Igrejas analisadas consideram o papel e a função do masculino e do feminino vinculado ao matrimônio, e consequente maternidade e paternidade.

O Papa João Paulo II, de acordo com Salzman e Lawler,associa um significado ontológico ao sexo masculino e ao feminino, com as respectivas implicações normativas (absolutas) para o gênero no matrimônio e na Igreja. Segundo o relato da criação, no Gênesis,revela "a verdade fundamental (...) relativa ao homem criado como homem e mulher à imagem e semelhança de Deus". Revela a igualdade entre homem e mulher, mas sua natureza física distinta envolve papéis de gênero distintos, tanto no matrimônio como na Igreja. "O matrimônio é definido em termos de complementaridade masculinofeminino, pelo qual as mulheres são conclamadas a trazer plena dignidade à maternidade e à vida conjugal" (SALZMAN, LAWLER, 2012, p. 167, grifos do autor).

No que se refere à "ideologia de gênero", 6 estudantes não sabem nada, 3 sabem pouco, 33 conhecem algumas questões e 18 conhecem mais ou menos. Se considerarmos o número de estudantes que declaram não saber nada, os que sabem pouco e aqueles que sabem medianamente, chega-se a 60 estudantes que tem pouco conhecimento sobre o tema. Os que declararam muito conhecimento foram 7 estudantes. Os que declararam conhecimento razoável/bom foram 51, e 3 não responderam. Isso representa que são mais os que sabem pouco (60 estudantes) do que os que sabem razoavelmente bem (58 estudantes). É curioso, pois o tema foi um dos principais "motes" da campanha eleitoral de 2018, tanto por parte de quem defendia a proposta quanto daqueles que fizeram oposição ao conceito, composições presentes na grande mídia social. Ao considerar as respostas dos estudantes, podemos pensar que os discursos ficaram restritos aos púlpitos e parecem não ter conseguido chegar até os estudantes que estavam nas universidades. Qual é a relação que as lideranças religiosas estão estabelecendo com os (as) estudantes no que diz respeito a gênero? Qual a relação que estabelecem entre questões de gênero, ideologia de gênero e educação? Não houve manifestações escritas pelos (as) estudantes que indicassem uma posição mais radicalizada sobre o tema.

Foi solicitado que os estudantes indicassem o seu grau de concordância com algumas questões. Primeira: a escola precisa estar preparada para discutir as questões de gênero. Nas respostas dos estudantes, 5 não concordam em absoluto; 2 pouca concordância; 12 concordam mais ou menos; 15 boa/razoável concordância; 85 concordam plenamente, representando 70,25\%; e 2 estudantes não responderam.

Sobre o grau de concordância quanto à questão: não é papel da escola discutir temas de gênero: 66 estudantes $(54,55 \%)$ não concordam com esta afirmação; 23 
concordam pouco; 14 concordam mais ou menos; 6 boa/razoável concordância; apenas $9,7,44 \%$, concordam plenamente; e 3 estudantes não responderam.

Foi solicitado que os (as) estudantes escrevessem, três palavras que representassem a sua concepção acerca de gênero como tema a ser tratado na escola. Uma das palavras de destaque foi: respeito, citada 12 vezes, sendo que em uma das citações, teve um enfoque de posição evidentemente contrária, pois, o (a) estudante escreveu: "em vez de discutir gênero tem que ensinar respeito pelo próximo". Desse modo cabe indagar qual seria a concepção de respeito do estudante? O conceito respeito pode ter uma interpretação "enviesada", pois, muitas vezes, na solicitação de respeito familiar, genitores podem esconder conflitos profundos, tais como violência doméstica, incestos, pedofilia entre outros. É no interior de famílias que violências acontecem, e por parte daqueles de quem se esperava amor e proteção. Entre as demais palavras citadas estão: identidade (12 vezes), igualdade (12 vezes), preconceito ( 9 vezes); família (8 vezes), aceitação (7 vezes), empatia, (7 vezes), conscientização. Uma das colocadas entre as menos citadas foi a palavra ideologia, escrita de uma forma que deixa evidente que o (a) estudante não está alinhado (a) ao campo religioso, ao dizer que "ideologia de gênero não existe".

\section{Escola sem partido}

Perguntamos aos estudantes se eles (as) conheciam o tema da Escola Sem Partido (ESP). Obtivemos as seguintes respostas, somadas as quatro turmas pesquisadas: 56,20\%, ou seja 68 estudantes, afirmam conhecer o tema; 40,50\%, ou 49 estudantes, não conhecem ou não ouviram falar sobre o assunto; 1,65\%, 2 alunos (as), ouviram falar; e 1,65\%, 2 alunos (as), não responderam.

Quando questionados se concordavam com a proposta da ESP, 47,93\% (58 estudantes) disseram que não e apenas $10,74 \%$ (13 estudantes) disseram sim. Não responderam 49 pessoas, ou 40,50\%. Um estudante afirmou concordar parcialmente.

Os (as) estudantes que participaram da pesquisa, conforme os dados apontaram, exercem, na sua grande maioria, práticas cristãs e, portanto, devem ter consciência dos posicionamentos das suas respectivas Igrejas no que diz respeito à moral sexual cristã, que é prescritiva para uma conduta aceitável no mundo. No entanto, a obediência não é automática, é muito mais complexa, pois diz respeito à forma como cada um (a) entende e percebe o mundo, acionando critérios que definem suas escolhas pessoais, ou seja, são "os modos de subjetivação" (FOUCAULT, 1999). Selecionamos frases de duas estudantes do campo religioso estudado, que explicitaram livremente o que pensam sobre as questões de gênero:

Preconceito surge da falta de informação e conhecimento sobre um assunto. O estudante da educação básica precisa conhecer o assunto para evitar que o preconceito perpetue em nossa sociedade.

\section{CONSIDERAÇÕES FINAIS}

Os dados aqui apresentados permitem não só uma aproximação do campo de pesquisa, mas demonstrou o que os (as) estudantes entendem e pensam sobre as teorias 
de gênero, e como as representações de gênero do campo religioso não encontram suporte ou alinhamento automático entre os (as) estudantes do curso de Pedagogia, mesmo que estes tenham declarado práticas religiosas.

O debate posto na conjuntura política e religiosa contemporânea, com posições radicalizadas, de um lado e de outro, promove a estigmatização do campo religioso, pressupondo que todas as pessoas que dele fazem parte sejam necessariamente conservadoras, reacionárias ou atrasadas. De outro, pressupõe que o campo de gênero é composto por pessoas "tresloucadas", "endemoniadas", "pesquisadores (as) questionáveis", na mira da inquisição.

A pesquisa demonstrou que não é bem assim. Na maioria dos argumentos e escolhas não estavam postas posições radicalizadas com relação às teorias de gênero, e não pareceu que há uma visão taxativa de doutrinação, seja política, religiosa, de gênero ou qualquer outra. A discussão que pretendem fazer não tem nada a ver com doutrinação, mas, ao que parece, revelam o compromisso e possibilidade de contribuir para um mundo melhor.

Mesmo dado o nível de complexidade que as questões de gênero apresentam e sobre as quais as igrejas demonstraram objeções públicas de discussão nas escolas, especialmente com a retirada do conceito de gênero e orientação sexual dos Planos de Educação, podemos constatar nas declarações dos (as) estudantes de Pedagogia, que, mesmo professando e exercendo práticas religiosas, tendem para atitudes de "insubordinação", ou à prática da "objeção de consciência". Isto talvez possa significar não seguir "ao pé da letra" as orientações eclesiais de suas respectivas Igrejas, pelo menos no que diz respeito às questões de gênero. Na prática é o que já acontece com relação aos uso dos contraceptivos não naturais, sobre o aborto, sexo fora do casamento, divórcio, entre outras práticas condenáveis pelas Igrejas, mas realizáveis adotadaspor parte de muitos de seus fiéis.

As normativas das Igrejas estudadas insistem nas afirmativas sobre a "ideologia de gênero", mas o discurso parece ter pouco alcance, pois, não consegue convencer a todos os seus fiéis. Se desejarem formar um corpo docente alinhado com suas propostas de combate ao gênero, vão ter que se desafiar a pensar numa outra forma, pois os estudantes cristãos ora em formação, em sua maioria, demonstraram concordância com a discussão do conceito de gênero nas escolas. Talvez cientes dessa "rebeldia", a Igreja Assembléia de Deus já constituiu espaço próprio de formação de docentes. Em agosto de 2005 inaugurou a Faculdade Evangélica de Tecnologia, Ciências e Biotecnologia (FAECAD), no Rio de Janeiro. E entre os cursos mais divulgados na página da instituição no facebook, estão os cursos de Pedagogia e Teologia.

\section{REFERÊNCIAS}

ALENCAR, Gedeon F. de. Assembléias brasileiras de Deus: teorização, história e tipologia - 1911 a 2011. Tese apresentada no Programa de Pós-Graduação em Ciências da Religião da Pontifícia Universidade Católica de São Paulo. PUC SP, 2012.

BUTLER, Judith. Corpos que pesam: sobre os limites discursivos do "sexo". In: LOURO, Guacira Lopes (org.). O corpo educado: pedagogias da sexualidade. Belo Horizonte: Autêntica, 1999, p. 151-172. 
CHARTIER, Roger. História Cultural: entre práticas e representações. São Paulo: DIFEL, 1990.

CONFERÊNCIA EPISCOPAL PERUANA. 1998. Lima, Peru. La ideologia de gênero: sus peligros y alcances. Disponível em: $<$ https://img.cancaonova.com/noticias/pdf/281960_IdeologiaDeGenero_PerigosEAlcan ces_ConferenciaEpiscopalPeruana.pdf> . Acesso em: 10 jan. 2019.

FAJARDO, Maxwell Pinheiro. "Onde a luta se travar": a expansão das Assembléias de Deus no Brasil urbano (1946-1980). Tese apresentada à Faculdade de Ciências e Letras de Assis, UNESPE - Universidade Estadual Paulista, para obtenção do título de Doutor em História (Área do Conhecimento História e Sociedade). Assis, 2015.

FALQUET, Jules. Por uma anatomia das classes de sexo: Nicole-Claude Mathieu ou a consciência das oprimidas. Lutas sociais [online]. São Paulo, jan./jun. 2014, v.18 n.32, p. 09-23. Disponível em: <https://revistas.pucsp.br/ls/article/view/25688/18324>. Acesso em: 19 jan. 2019.

FORCANO, Benjamin. Nova ética sexual. CANABARRO, Nelson (trad.). São Paulo: Musa Editora, 1996.

FOUCAULT, Michael. Microfísica do poder. Rio de Janeiro: Graal, 1999.

JESUS, Jaqueline Gomes. Orientações sobre identidade de gênero: conceitos e termos - Guia técnico sobre pessoas transexuais, travestis e demais transgêneros, para formadores de opinião. Brasília, 2012. Disponível em: <http://www.diversidadesexual.com.br/wp-content/uploads/2013/04/G\%C3\%8ANEROCONCEITOS-E-TERMOS.pdf >. Acesso em: 02 jan. 2019.

LOPES, Marcelo. Metanoia Pentecostal: sinais de uma primavera educacional na Assembléia de Deus no Brasil. Tese de doutorado apresentada ao Programa de PósGraduação em Ciências da Religião, Sociedade e Cultura do Instituto de Ciências Humanas da Universidade Federal de Juiz de Fora, 2018. Disponível em: <http://repositorio.ufjf.br:8080/xmlui/bitstream/handle/ufjf/6714/marcelolopes.pdf?sequ ence $=1 \&$ isAllowed=y $>$. Acesso em: 08 jan. 2019.

LOURO, Guacira Lopes. Gênero, sexualidade e educação: uma perspectiva pósestruturalista. Petrópolis: Vozes, 1997.

PEDRO, Joana Maria. Traduzindo o debate: o uso da categoria gênero na pesquisa história. Revista História, v. 24, n. 1, p. 77-98. Disponível em: <http://dx.doi.org/10.1590/S0101-90742005000100004>. Acesso em: 27 jan. 2018. 
PRINCÍPIOS DE YOGYAKARTA. Principios sobre a aplicacao da legislacao internacional de direitoshumanos em relacao a orientacao sexual e identidade de genero. $2007 . \quad$ Disponível em: <http://www.dhnet.org.br/direitos/sos/gays/principios_de_yogyakarta.pdf >. Acesso em: 02 abr.2018.

REIS, Tony. EGGERT, Edla. Ideologia de Gênero: uma falácia construída sobre os Planos de Educação brasileiros. Educação \& Sociedade, Campinas, jan.-mar, 2017, v. 38 , n. 138 , p.9-26.

SCOTT, Joan W. Gênero: uma categoria útil para a análise histórica. In.: DABAT, C.; ÁVILA, M. B. (Trad.). Recife: SOS: Corpo e Cidadania, 1995. Disponível em: $<$ https://edisciplinas.usp.br/pluginfile.php/1737847/mod_resource/content/1/Scott_g\% C3\%AAnero\%20uma\%20categoria\%20\%C3\%BAtil\%20para\%20a\%20an\%C3\%A1lis e\%20hist\%C3\%B3rica.pdf>. Acesso em: 10 jan. 2019.

ROSEMBERG, Fúlvia. Expansão da educação infantil e processos de exclusão. Cadernos de Pesquisa, n.107, São Paulo, jul.1999. Disponível em: <http://www.scielo.br/pdf/cp/n107a01.pdf>. Acesso em: 10 fev. 2019.

SALZMAN, Todd A.; LAWLER, Michael G. A pessoa sexual: por uma Antropologia católica renovada. São Leopoldo: Ed. UNISINOS, 2012. 430 p.

SCOTT, Joan W. Gênero: Uma Categoria Útil para a Análise Histórica. DABAT, C.; ÁVILA, M. B. (Trad.). Recife: SOS: Corpo e Cidadania, 1995. Disponível em: <https://edisciplinas.usp.br/pluginfile.php/1737847/mod_resource/content/1/Scott_g\%C 3\%AAnero\%20uma\%20categoria\%20\%C3\%BAtil\%20para\%20a\%20an\%C3\%A1lise\% 20hist\%C3\%B3rica.pdf>. Acesso em: 10 jan. 2019.

SEVERINO, Antonio Joaquim. Metodologia do trabalho científico. 24. ed. São Paulo: Cortez, 2016

SILVA, Amanda. Da "ideologia de gênero" à família heteronormativa: uma análise do Plano Municipal de Educação. Dissertação apresentada no Programa de Pós-Graduação em Educação, na Universidade Federal do Paraná - UFPR. Curitiba, 2017.

TADVALD, Marcelo. Veredas do Sagrado: Brasil e Argentina no contexto da transnacionalização religiosa. Porto Alegre: Cirkula Editora, 2015.

TAMANINI, M.; BOSCHILIA, R.; SCHWENDLER, S. F. (orgs). Teorias e políticas de gênero na contemporaneidade. Curitiba: UFPR, 2017.

Recebido em: 07/04/2019

Aprovado em: 04/04/2019 